\title{
Wall-associated Protein Antigens of Streptococcus mutans
}

\author{
By R. R. B. RUSSELL \\ Dental Research Unit, Royal College of Surgeons of England, \\ Downe, Orpington, Kent BR6 7JJ
}

(Received 8 January 1979)

\begin{abstract}
When heat-killed whole organisms of Streptococcus mutans strain Ingbritt (serotype $c$ ) were injected into rabbits, antibodies to at least 12 antigens were detectable by crossed immunoelectrophoresis. In contrast, when rabbits were immunized with organisms which had been subjected to extraction with the detergent sodium dodecyl sulphate (SDS), antibodies to only two protein antigens were found. These two proteins (A and B), while existing in a form apparently closely associated with peptidoglycan, could also be recovered from homogenates of whole organisms after sonication and from culture filtrates. Antigenic material was excreted throughout growth. SDS-polyacrylamide gradient gel electrophoresis showed A to have a molecular weight of 29000 , while B had a molecular weight of 190000 . Antigen B was purified to apparent homogeneity as judged by SDS-polyacrylamide gel electrophoresis and isoelectric focusing. All of six strains of serotype $c$ examined produced antigen B. Strains of serotypes $e$ and $f$ also produce antigenically identical proteins and strains of serotypes $d$ and $g$ produce proteins which cross-reacted with antigen B. Antigen B was specifically precipitated by rabbit antiserum to human heart tissue.
\end{abstract}

\section{INTRODUCTION}

Experiments from a number of laboratories have clearly shown that immunization of animals with Streptococcus mutans or its subcellular fractions can confer protection against dental caries induced by this organism (Bowen et al., 1976), but the mechanism of this protection and the bacterial antigens involved remain unknown. For the development of an effective vaccine it is desirable to identify the antigen(s) involved in eliciting protective antibody, and the means by which protection is conferred. Identification and purification of such an antigen would aid in the understanding of the mechanism of protection, allow monitoring of vaccine preparations for efficacy, and facilitate study of its relationship with any toxic components of a crude vaccine. Of particular concern in the case of $S$. mutans is the demonstration of an antigenic relationship between $S$. mutans and human heart tissue (van de Rijn et al., 1976).

An earlier report from this laboratory described successful protection of monkeys immunized with walls of $S$. mutans (Bowen et al., 1975). Walls treated with trypsin, on the other hand, fail to confer protection suggesting that the protective antigen might be protein in nature (Colman \& Cohen, 1979). The present paper describes studies of proteins associated with $S$. mutans walls and the purification of one wall-associated antigen. The purified antigen is also demonstrated to be antigenically related to human heart tissue.

\section{METHODS}

Organisms. Strains of $S$. mutans representing serotypes a to $g$ (Bratthall, 1969; Perch et al., 1974) were OMZ-61 [a]; FAI[b]; Ingbritt, NCTC 10449, FW293, GS-5, OMZ-70 and C67-1 [all $c]$; B13[d]; P4[e]; $151[f] ; \mathrm{K} 1[\mathrm{~g}]$. The sources of these strains have been presented before (Russell, 1976a).

Media. The media used were Todd-Hewitt Broth (Oxoid), Tryptone-yeast extract broth (Tryptone, $10 \mathrm{~g}$; 
yeast extract, $3 \mathrm{~g} ; \mathrm{NaCl}, 2 \mathrm{~g} ; \mathrm{K}_{2} \mathrm{HPO}_{4}, 2 \mathrm{~g}$; $\mathrm{NaHCO}_{3}, 1 \mathrm{~g}$; glucose, $5 \mathrm{~g}$; water, $\left.1 \mathrm{l}\right)$ and the chemically defined (CD) medium of Janda \& Kuramitsu (1976) supplemented with $0 \cdot 2 \%(\mathrm{w} / \mathrm{v}) \mathrm{Na}_{2} \mathrm{CO}_{3}$ (Terleckyj \& Shockman, 1975).

Antisera. New Zealand white rabbits (each 2 to $3 \mathrm{~kg}$ ) were used for the preparation of antisera. Injection schedules consisted of two or more intramuscular injections $(1 \mathrm{ml})$ at 3 week intervals, blood being taken 1 week after a booster. The immunogens used were as follows: (i) whole organisms - the organisms from a $20 \mathrm{ml}$ culture in Todd-Hewitt broth were collected by centrifugation, resuspended in $0.9 \mathrm{ml}$ phosphatebuffered saline and killed by heating at $60^{\circ} \mathrm{C}$ for $1 \mathrm{~h}$; (ii) sodium dodecyl sulphate (SDS)-extracted organisms - organisms grown as described above were suspended in $5 \mathrm{ml}$ of the solubilizing buffer of Laemmli (1970), placed in a boiling water bath for $20 \mathrm{~min}$, then washed three times with water by resuspension and centrifugation and finally suspended in $0.9 \mathrm{ml}$ phosphate-buffered saline; (iii) purified antigen B (see below) $50 \mu \mathrm{g}$ in $0.9 \mathrm{ml}$ phosphate-buffered saline. Aluminium hydroxide $(0.1 \mathrm{ml}$; Alu Gel $\mathrm{S}$, Serva) was added to all immunogens prior to injection. The immunoglobulin fraction of antisera was purified according to the method of Closs et al. (1975). Antiserum directed against human heart tissue (Hughes, 1978) was generously provided by Dr M. Hughes, Wellcome Research Laboratories, Beckenham, Kent.

Immunological techniques. Immunodiffusion was performed in $1 \%(\mathrm{w} / \mathrm{v})$ agarose (Type 1 ; Sigma) in $0.05 \mathrm{M}$-Tris/ $\mathrm{HCl}$ buffer, $\mathrm{pH} \mathrm{7.5,} \mathrm{on} \mathrm{glass} \mathrm{slides.} \mathrm{Rocket} \mathrm{and} \mathrm{crossed} \mathrm{immunoelectrophoresis} \mathrm{were} \mathrm{performed}$ according to the methods outlined by Axelsen et al. (1973) using Litex HSC agarose (International Enzymes) and the Tris/barbital buffer of Holmberg et al. (1975). For crossed immunoelectrophoresis experiments in which the first-dimension separation was in acrylamide gel, the 'laying-on' technique of Ekwall et al. (1976) was used, and after separation in SDS-containing gels, $1 \%(\mathrm{w} / \mathrm{v})$ Triton X-100 was included in the lower (non-antibody containing) zone of the slide (Converse \& Papermaster, 1975).

Polyacrylamide gel electrophoresis. Electrophoresis in the presence of SDS using the buffer system of Laemmli (1970) with $9 \%(\mathrm{w} / \mathrm{v})$ acrylamide in the separating gel was done in an apparatus built to the design of Studier (1973). For SDS-polyacrylamide gradient gel electrophoresis, the same buffer system and apparatus were used; the 6 to $20 \%$ acrylamide gradient was formed with a simple two-chamber mixing device.

For staining of proteins, gels were fixed in $12 \%(\mathrm{w} / \mathrm{v})$ trichloroacetic acid and stained in $0.2 \%(\mathrm{w} / \mathrm{v})$ Coomassie Brilliant Blue in acetic acid/ethanol/water (10:45:45, by vol.). Destaining was in the same solvent mixture using methanol instead of ethanol. Glycoproteins were stained by the periodate-Schiff method (Segrest \& Jackson, 1972) or periodate-dansyl hydrazine (Eckhardt et al., 1976).

Isoelectric focusing. Isoelectric focusing in slabs of $6 \%(\mathrm{w} / \mathrm{v})$ acrylamide was performed according to Wrigley (1971), using pH 3 to 5 ampholytes (Serva). Proteins were stained by method D of Vesterberg et al. (1977).

Antigen preparation. Proteins from culture filtrate were concentrated 100 -fold by bringing the filtrate to $65 \%$ saturation with $\left(\mathrm{NH}_{4}\right)_{2} \mathrm{SO}_{4}$ and standing for $16 \mathrm{~h}$ at $4{ }^{\circ} \mathrm{C}$. The precipitate formed was collected by centrifugation at $10000 \mathrm{~g}$, dissolved in $0.05 \mathrm{M}$-Tris $/ \mathrm{HCl}, \mathrm{pH} \mathrm{7.5}$, and dialysed for $24 \mathrm{~h}$ against this buffer. For the preparation of homogenates, organisms were suspended in the Tris buffer and subjected to ultrasonic disintegration with an MSE $150 \mathrm{~W}$ ultrasonic disintegrator at maximum output for $20 \mathrm{~min}$, the sample being cooled in an ice bath. Culture filtrate and homogenates were maintained frozen at a concentration of 2 to $3 \mathrm{mg}$ protein $\mathrm{ml}^{-1}$. Lancefield acid extracts and Rantz \& Randall autoclave extracts were prepared by the standard methods (Lancefield, 1933; Rantz \& Randall, 1955). For pronase treatment, antigens were incubated with $1 \mathrm{mg}$ pronase $\mathrm{ml}^{-1}(\mathrm{BDH})$ at $37^{\circ} \mathrm{C}$ for $2 \mathrm{~h}$, then placed in a boiling water bath for 5 min to inactivate the enzyme.

Purification of antigen B. Streptococcus mutans strain Ingbritt was grown for $20 \mathrm{~h}$ in CD medium at $37^{\circ} \mathrm{C}$. The organisms were removed by centrifugation at $10000 \mathrm{~g}$ followed by filtration through glass fibre (Whatman GF/D). Sodium azide $(0 \cdot 1 \%, w / v)$ was added and the culture filtrate was passed down a chromatography column ( $50 \mathrm{ml}$ bed volume) containing mutan and BioGel P2, prepared as described by McCabe \& Smith (1977), before being brought to $45 \%$ saturation with $\left(\mathrm{NH}_{4}\right)_{2} \mathrm{SO}_{4}$. The precipitate which formed during $16 \mathrm{~h}$ at $4{ }^{\circ} \mathrm{C}$ was collected by centrifugation, dissolved in $0.05 \mathrm{M}-\mathrm{Tris} / \mathrm{HCl}, \mathrm{pH} 7 \cdot 5$, and dialysed for $24 \mathrm{~h}$ against this buffer. Tris buffer (0.05 $\mathrm{M}, \mathrm{pH} \mathrm{7.5)}$ was used throughout the subsequent purification. The dialysed sample was applied to a column (19 ml bed volume) of DEAE-Sephadex A25 (Pharmacia) equilibrated with Tris buffer, and the column was washed with one bed-volume of buffer prior to elution with a linear gradient of 0 to $0.3 \mathrm{M}-\mathrm{NaCl}$ in Tris buffer. Fractions were collected and examined for the presence of antigen $\mathrm{B}$ by rocket immunoelectrophoresis into the antiserum directed against SDS-extracted organisms, and by SDS-polyacrylamide gel slab electrophoresis. Fractions eluting between $0 \cdot 07$ and $0 \cdot 1 \mathrm{M}-\mathrm{NaCl}$ were found to contain antigen $\mathrm{B}$, with only minor amounts of two other proteins being detected by electrophoresis. The fractions containing antigen were pooled and concentrated to approximately $1 \mathrm{mg}$ protein $\mathrm{ml}^{-1}$ by ultrafiltration with a Millipore immersible molecular separator before being applied to a column (200 ml bed volume) of Sepharose CL-6B (Pharmacia) equilibrated with Tris buffer. Antigen-containing fractions eluted from this column were pooled and are referred to as 'pure antigen $B$ '. 


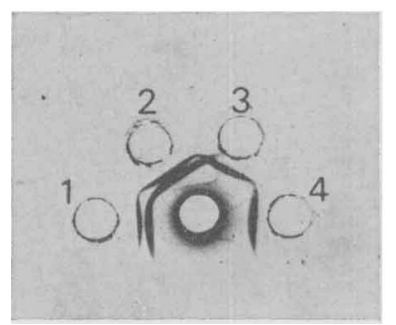

Fig. 1

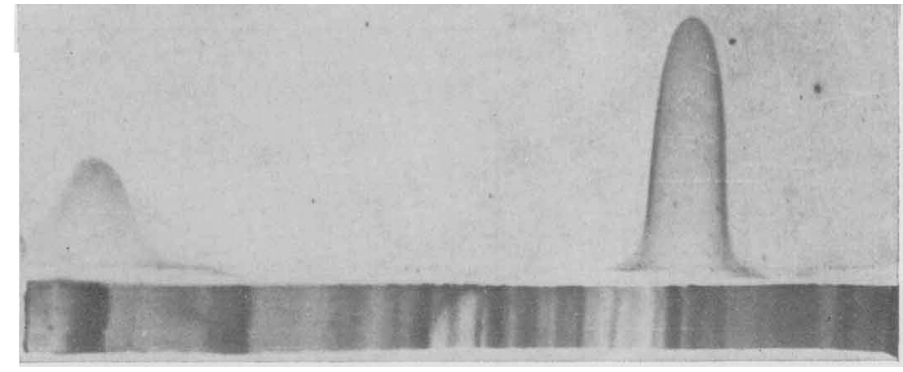

Fig. 2

Fig. 1. Immunodiffusion analysis of reactions between antiserum to SDS-extracted organisms (centre well) and culture filtrate (1), homogenate (2), Lancefield extract (3) and Rantz \& Randall extract (4) of $S$. mutans strain Ingbritt.

Fig. 2. Crossed immunoelectrophoresis into antiserum to SDS-extracted organisms of $S$. mutans culture filtrate antigens separated by SDS-gel electrophoresis. The stained strip of acrylamide along the bottom shows the location of protein bands after the first-dimension separation.

\section{RESULTS}

\section{Antigens of SDS-extracted organisms}

Rabbits immunized with $S$. mutans strain Ingbritt by the procedure described in Methods produce antibodies to a large number of antigens, and crossed immunoelectrophoresis experiments using a cell extract or concentrated culture supernatant as antigen revealed at least 12 antigen/antibody reactions. In contrast, when animals were immunized with the SDS-extracted organisms, antibodies to only two antigens could be detected.

These antigens, designated A and B, could both be detected in a homogenate prepared by sonication of whole organisms and in concentrated culture filtrate, while one of them (subsequently found to be antigen B) was also readily detectable in Lancefield and Rantz \& Randall extracts (Fig. 1). Treatment of a culture filtrate sample with pronase or trypsin completely destroyed both antigens, indicating that their antigenic determinants were protein in nature.

\section{Characterization of antigens $A$ and $B$}

Culture filtrate proteins were separated by SDS-gel electrophoresis (Fig. 2) or by isoelectric focusing, and then electrophoresed in the second dimension into antiserum raised against SDS-extracted organisms. Comparison of the mobilities of the two antigens with those of molecular weight standards in SDS-gel electrophoresis, or SDS-gradient gel electrophoresis, showed the molecular weights of antigens A and B to be 29000 and 190000 , respectively. The standards used were rabbit myosin (200000), $\beta$-galactosidase (116000), phosphorylase A (94000), bovine serum albumin (68000), ovalbumin (43000) and chymotrypsinogen A (25700).

Antigen B appeared to be a glycoprotein, as it was weakly stained by both the periodateSchiff reagent and by dansyl hydrazine. The isoelectric points for antigens A and B were estimated to be $4 \cdot 3$ and $5 \cdot 4$, respectively.

\section{Release of antigens $A$ and $B$}

The culture filtrate used for the experiments described above was prepared from a culture which had reached the stationary phase of growth. To investigate further the kinetics of release of antigens $\mathrm{A}$ and $\mathrm{B}$, samples were taken at various stages of growth and concentrated 100 -fold by $\left(\mathrm{NH}_{4}\right)_{2} \mathrm{SO}_{4}$ precipitation or by dialysis followed by lyophilization. The amount of antigen in each sample was then determined by quantitative rocket immunoelectrophoresis. The results showed that both antigens were released into the growth medium throughout growth (Fig. 3). 


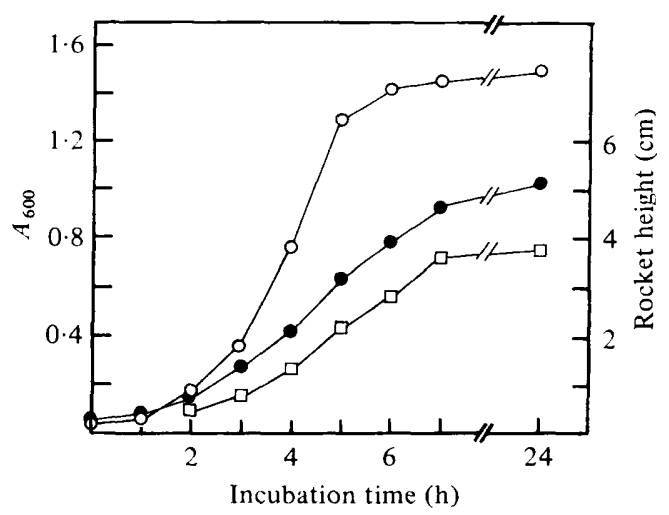

Fig. 3. Growth of $S$. mutans strain Ingbritt in Tryptone-yeast extract medium and the antigen content of the culture filtrate as determined by rocket immunoelectrophoresis: $O$, absorbance; , antigen $\mathrm{B} ; \square$, antigen $\mathrm{A}$.

\section{Purification of antigen $B$}

The protein composition of culture filtrates is simpler than that of cell extracts, so antigen $\mathrm{B}$ was purified from the filtrate of a culture in $\mathrm{CD}$ medium by a procedure involving affinity chromatography, fractional $\left(\mathrm{NH}_{4}\right)_{2} \mathrm{SO}_{4}$ precipitation, ion-exchange chromatography and gel filtration. The affinity chromatography on mutan was included to remove glucosyltransferase, which was found in preliminary experiments to co-purify with antigen $B$. The final product gave a single band on SDS-gel electrophoresis and also on isoelectric focusing.

\section{Antigens of other strains}

Monospecific antiserum directed against antigen $\mathbf{B}$ was used in immunodiffusion experiments to look for the presence of this, or cross-reacting, antigens in strains of $S$. mutans other than Ingbritt. Antigens from five other strains of serotype $c$ gave a line of identity with antigen B from Ingbritt, and cross-reactions were observed with other serotypes (Fig. 4). The strains of serotypes $c, e$ and $f$ were identical. This agrees with the finding that these three serotypes fall into a single genetically homogeneous group (Coykendall, 1974) and are known to have matching protein patterns on SDS-gel electrophoresis (Russell, 1976a). Members of serotypes $d$ and $g$ are also in a single genetic group, and they were found to possess a common antigen showing a line of partial identity with antigen $\mathrm{B}$. Where present, crossreacting antigens were detectable in homogenates, culture filtrates or Lancefield extracts. No antigens cross-reacting with antigen $\mathrm{B}$ were found in the strains of serotypes $a$ and $b$. Experiments with strain $\mathrm{K} 1$ (serotype $g$ ) have shown that the antigen from this strain crossreacting with antigen $B$ is also a wall-associated protein of high molecular weight.

\section{Relationship between antigen $B$ and glucosyltransferase}

Because of the observation that glucosyltransferase and antigen $B$ behaved similarly during purification procedures, together with the fact that glucosyltransferase of $S$. mutans strain Ingbritt has a molecular weight approaching that of antigen B (Russell, 1979), we investigated the possibility that they were related. The techniques used for studying glucosyltransferase have been described elsewhere (Russell, 1979). The following lines of evidence have shown that antigen B is quite distinct from glucosyltransferase: (i) no glucosyltransferase activity could be detected in acrylamide gels at a position corresponding to that of antigen $\mathrm{B}$; (ii) antigen $\mathbf{B}$ purified as described above or by immunoaffinity chromatography (unpublished observations) had no glucosyltransferase activity; (iii) antigen B did not bind to affinity columns of immobilized glucan while glucosyltransferase did; (iv) antiserum to antigen B 


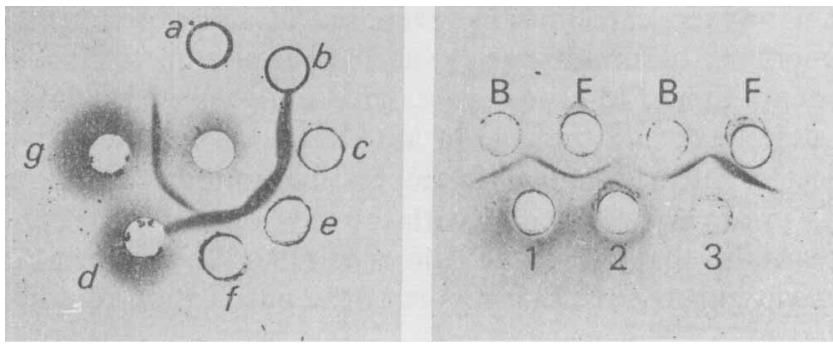

Fig. 4

Fig. 5

Fig. 4. Immunodiffusion analysis of reactions between antiserum to purified antigen $B$ (centre well) and concentrated filtrates of strains of the serotypes $a, b, c, e, f, d$ and $g$.

Fig. 5. Immunodiffusion analysis of antisera to human heart tissue (1), antigen $F$ (Hughes, 1979) (2) and purified antigen $B(3)$ against antigens $B$ and F.

did not precipitate glucosyltransferase; (v) antiserum to purified glucosyltransferase did not precipitate antigen $B$.

\section{Antigenic cross-reactivity of antigen $B$ with heart}

Hughes (1979) has recently reported that there are at least two components of $S$. mutans strain Ingbritt which show antigenic cross-reactivity with human heart tissue, and he has isolated one of the cross-reactive antigens. This antigen, which has not yet been physically characterized, has been termed ' $F$ '. Figure 5 shows that antigen $B$ is precipitated by antiserum directed against heart tissue. It is also apparent that antigen $\mathrm{B}$ is immunologically identical to the antigen $\mathrm{F}$ isolated independently by Hughes.

\section{DISCUSSION}

The anionic detergent SDS is a powerful dissociating agent, and all except covalent bonds are believed to be split by SDS at $100^{\circ} \mathrm{C}$ (Maizel, 1971). The fact that antigens A and $B$ remain insoluble after SDS extraction therefore suggests that they exist in a form covalently bound to peptidoglycan. Although in the present study SDS-extracted whole organisms were used, the same two antigens were found when the starting material was walls prepared by Mickle disintegration (unpublished observations). The detergent SDS appears to be removing all other antigens rather than exposing hidden antigens (as seems to be the case in exposure of streptococcal $M$ protein by acid extraction; Beck \& BergnerRabinowitz, 1977) since all rabbits immunized with unextracted whole bacteria had formed antibodies to antigens A and B. The fact that these wall-associated antigens can also be recovered from cell-free culture filtrates resembles the behaviour of wall proteins of a number of other bacteria, including protein A of Staphylococcus aureus (Movitz, 1976), M protein of group A streptococci (Pinney \& Widdowson, 1977) and the murein-lipoprotein of Escherichia coli (Braun, 1975; Russell, 1976b). The release of wall proteins greatly simplified their purification, but it is important to remember that there may be slight differences between the wall-bound and free forms of the protein, and also that there may exist other wall-bound antigens which are not readily released into the culture medium.

The fact that antigen $B$ is present in Lancefield acid extracts, together with the observation that a strong immune response to it is obtained when whole cells are injected into rabbits, suggests that this antigen could be responsible for some of the non-specific crossreactions between serotypes of $S$. mutans (Bratthall, 1969).

Antigen $B$ is present in both whole organisms and wall preparations which have been found capable of conferring protection against caries in experimental monkeys (G. Colman \& R. R. B. Russell, unpublished observations). Antibodies to antigen B may be involved 
in this protection. However, care must be exercised in any experiments designed to test antigen $B$ as a component of an anti-caries vaccine because of its demonstrated antigenic relationship with heart tissue. Many cross-reactive antigens of bacteria and mammalian tissues have been described, and the role of auto-antibodies induced by such antigens in disease is the subject of intensive study (Lyampert \& Danilova, 1975). An involvement of prior infection with group A streptococci with the development of rheumatic fever is well established, and it was this that led van de Rijn et al. (1976) to seek heart cross-reactivity in $S$. mutans. The present paper is the first report of the purification of a heart cross-reactive antigen from $S$. mutans.

I wish to thank Dr M. Hughes, Wellcome Research Laboratories, for providing the antiserum directed against human heart.

\section{REFERENCES}

Axelsen, N. H., Kroll, J. \& Weeke, B. (1973). $A$ Manual of Quantitative Immunoelectrophoresis. Oslo: Universitatetsforlaget.

BECK, A. \& BERGNER-RABINOWITZ, S. (1977). Preparation of type-specific anti-M streptococcal sera by immunization with acid-hydrolyzed cells. Journal of Laboratory and Clinical Medicine 89, 1120-1124.

Bowen, W. H., Cohen, B., Cole, M. F. \& Colman, G. (1975). Immunisation against dental caries. British Dental Journal 139, 45-58.

Bowen, W. H., Genco, R. J. \& O'Brien, T. C. (editors) (1976). Immunological Aspects of Dental Caries. London: Information Retrieval Limited.

Bratthall, D. (1969). Immunodiffusion studies on the serological specificity of streptococci resembling Streptococcus mutans. Odontologisk revy 20, 231-242.

Braun, V. (1975). Covalent lipoprotein from the outer membrane of Escherichia coli. Biochimica et biophysica acta 415, 335-377.

Closs, O., Harboe, M. \& Wassum, A. M. (1975). Cross-reactions between mycobacteria. Scandinavian Journal of Immunology 4, Suppl, 2, 173-185.

Colman, G. \& CoHen, B. (1979). Immunization of monkeys (Macaca fascicularis) with Streptococcus mutans. In Pathogenic Streptococci, pp. 214-215. Edited by M. T. Parker. Chertsey: Reedbooks.

Converse, C. A. \& Papermaster, D.S. (1975). Membrane protein analysis by two-dimensional immunoelectrophoresis. Science 189, 469-472.

Coykendall, A. L. (1974). Four types of Streptococcus mutans based on their genetic, antigenic and biochemical characteristics. Journal of General Microbiology 83, 327-338.

Eckhardt, A. E., Hayes, C. E. \& Goldstein, I. J. (1976). A sensitive fluorescent method for the detection of glycoproteins in polyacrylamide gels. Analytical Biochemistry 73, 192-197.

Ekwall, K., Söderholm, J. \& Wadström, T. (1976). Disc-crossed immunoelectrophoresis. A simple 'laying-on' technique permitting the use of commercially available agarose. Journal o, Immunological Methods 12, 103-115.

Holmberg, K., Nord, C.-E. \& Wadström, T. (1975). Serological studies of Actinomyces israeli by crossed immunoelectrophoresis: standard antigen-antibody system for $A$. israelii. Infection and Immunity 12, 387-397.

HuGHES, M. (1979). Cross-reaction of Streptococcus mutans with heart-tissue antigens. In Pathogenic Streptococci, pp. 222-223. Edited by M. T. Parker. Chertsey: Reedbooks.

JANDA, W. M. \& Kuramitsu, H. K. (1976). Regulation of extracellular glucosyltransferase production and the relationship between extracellular and cell-associated activities in Streptococcus mutans. Infection and Immunity 14, 191-202.

LAEMMLI, U. K. (1970). Cleavage of structural proteins during the assembly of the head of bacteriophage T4 Nature, London 227, 680685.

LANCEFIELD, E. (1933). A serological differentiation of human and other groups of hemolytic streptococci. Journal of Experimental Medicine 57, 571595.

Lyampert, I. M. \& Danilova, T. A. (1975). Immunological phenomena associated with crossreactive antigens of micro-organisms and mammalian tissues. Progress in Allergy 18, 423477.

MaIzel, J. V. (1971). Polyacrylamide gel electrophoresis of viral proteins. Methods in Virology 5 , 179-246.

MCCabe, M. M. \& Smith, E. E. (1977). Specific method for the purification of Streptococcus mutans dextransucrase. Infection and Immunity 16, $760-765$.

Movitz, J. (1976). Formation of extracellular protein A by Staphylococcus aureus. European Journal of Biochemistry 68, 291-299.

Perch, B., KJems, E. \& Ravn, T. (1974). Biochemical and serological properties of Streptococcus mutans from various human and animal sources. Acta pathologica et microbiologica scandinavica B82, 357-370.

Pinney, A. M. \& Widdowson, J. P. (1977). Characteristics of the extracellular $M$ proteins of group-A streptococci. Journal of Medical Microbiology 10, 415-429.

RANTZ, L. A. \& RANDALL, E. (1955). Use of autoclaved extracts of hemolytic streptococci for serological grouping. Stanford Medical Bulletin 13, 290-291. 
RiJn, I. VAN DE, Bleiweis, A. S. \& ZABRiskie, J. B. (1976). Antigens in Streptococcus mutans cross reactive with human heart muscle. Journal of Dental Research 55, Special Issue C, C59-C64.

RuSSELl, R. R. B. (1976a). Classification of Streptococcus mutans by SDS gel electrophoresis. Microbios Letters 2, 55--59.

Russell, R. R. B. $(1976 b)$. Two-dimensional SDSpolyacrylamide gel electrophoresis of heatmodifiable outer-membrane proteins. Canadian Journal of Microbiology 22, 83-91.

RuSSELL, R. R. B. (1979). Glycosyltransferases of Streptococcus mutans strain Ingbritt. Microbios 23, 135-146.

Segrest, J. P. \& JACKson, R. L. (1972). Molecular weight determination of glycoproteins by poly- acrylamide gel electrophoresis in sodium dodecyl sulphate. Methods in Enzymology 28, 54-63.

Studier, F. W. (1973). Analysis of bacteriophage T7 early RNAs and proteins on slab gels. Journal of Molecular Biology 79, 237-248.

TerleckyJ, B. \& Shockman, G. D. (1975). Growth of several cariogenic strains of oral streptococci in a chemically defined medium. Infection and Immunity 11, 649-655.

VesterberG, O., Hansen, L. \& Suösten, A. (1977). Staining of proteins after isoelectric focusing in gels by new procedures. Biochimica et biophysica acta 491, 160-166.

WRIGLEY, C. W. (1971). Gel electrofocusing. Methods in Enzymology 22, 559-564. 